\title{
EL PROBLEMA OCUPACIONAL EN LAS AREAS RURALES Y SU CONCEPTUALIZACIÓN
}

\author{
TERESA RENDóN \\ El Colegio de México
}

\section{Algunas CONSIDERACiones SObRe la teoría DEL SUbEMPleo}

EN LA ACTUALIDAD, se identifica al problema de la subutilización de la fuerza de trabajo como uno de los más importantes del país no sólo en las esferas académicas, sino que se ha convertido en una de las preocupaciones principales del gobierno federal, al grado que el aumento de las oportunidades de empleo se establece como uno de los objetivos básicos de la actual política de desarrollo, junto con el incremento de la producción nacional, la disminución de la dependencia respecto del exterior y una más equitativa distribución del ingreso. Sin embargo, en el momento en que esta política se traduce en medidas concretas, el objetivo de mayor empleo parece perderse, lo que puede atribuirse de manera principal al desconocimiento de mecanismos para el logro de tal objetivo, que a su vez se deriva de un desconocimiento del problema que se pretende resolver.

El fenómeno del empleo en México, y en especial en las áreas rurales no ha sido estudiado con la sistematización y profundidad que su complejidad requiere; debido más que a un simple problema de escasez de información (como en ocasiones se afirma), a la carencia de un marco conceptual adecuado. La dificultad principal para la interpretación realista del problema ocupacional en los países de menor desarrollo relativo, radica en la orientación misma en que se ha basado tal interpretación: la teoría del subempleo.

Aun cuando al término "subempleo" y a sus sinónimos se le ha dado diversos significados, en esencia se le ha utilizado para describir una situación en que la fuerza de trabajo empleada en ciertas actividades económicas permanece ociosa durante una parte del día, mes, semana o año; o (si trabaja) es improductiva (su productividad marginal es igual a cero). Esto implica que si en un proceso de producción determinado la fuerza de trabajo disminuye, podría obtenerse la misma cantidad de producto si la fuerza de trabajo que queda trabaja un tiempo mayor. Esta inferencia constituye la teoría implícita en el concepto de subempleo. ${ }^{1}$

1 Gunnar Myrdal, Asian Drama. An Inquirity into Poverty of Nations, Apén- 
A manera de ejemplo, baste con citar la definición de subempleo dada por los expertos de las Naciones Unidas en un informe presentado en 1951, pero cuyos preceptos (pese a las innumerables críticas de que han sido objeto), aún están presentes en el análisis de la subutilización de la fuerza de trabajo de los países de menor desarrollo. Dicho informe señala:

"los subempleados son las personas que trabajan por su cuenta y son tan numerosos, respecto de los recursos a que aplican su trabajo, que si cierto número de ellas fuera retirado y transferido a otros sectores de la economía, el producto del sector del cual fueron sustraídas no disminuiría, aún $\sin$ que tuviera lugar una reorganización significativa (del trabajo) o una sustitución significativa de capital (cambio tecnológico)".2

De acuerdo con esta distinción, se supone que el subempleo es involuntario; los trabajadores estarían dispuestos a trabajar durante más tiempo y más productivamente si tuvieran la oportunidad de hacerlo. Por otra parte, no queda claro si la subutilización del trabajo consiste en ociosidad de una parte de los trabajadores o en que su trabajo no produce nada, o ambas cosas.

La mayor parte de los investigadores que adoptan esta orientación consideran que la productividad marginal del trabajo es igual a cero (algunos señalan incluso que es negativa, mientras para otros es positiva pero muy baja).

Además de que la tesis de productividad marginal igual a cero no es realista y se opone al supuesto del carácter involuntario que se atribuye al subempleo, ${ }^{3}$ carece de sentido establecer que la productividad marginal igual a cero (negativa, o muy reducida) sea una condición para el subempleo.

La relación que se supone entre productividad marginal y subempleo

dice 6, "A Critical Appraisal of the Concept and Theory of Underemployment", Londres, Penguin Books, 1968, pp. 2041-2044.

2 United Nations, Department of Economic Affairs, Measures for the Economic Development of Under-Development Countries, Nueva York, mayo de 1951. Citado por G. Myrdal, op. cit., p. 2044.

3 "Contrariamente a los supuestos en los que se fundamenta la teoría del subempleo, el hecho de trabajar 'cuesta' algo, y es irrealista suponer que se va a proporcionar una unidad más de fuerza de trabajo si el esfuerzo que esto implica no rinde ningún fruto. Existe, por lo tanto, un límite a la disponibilidad de la fuerza de trabajo, que se alcanza necesariamente antes de que el producto marginal de una unidad de trabajo sea rebasado por el esfuerzo que representa su aplicación. El subempleo se da, pues, por definición, con una productividad marginal del trabajo positiva. Con esto se destruye el supuesto del carácter involuntario del desempleo, ya que la estimación del valor de su esfuerzo por el propio trabajador es la que determina el punto más allá del cual se vuelve irracional seguir trabajando." Marielle Martínez, "Formas y grados de utilización de sus recursos por las unidades domésticas campesinas", Guión de investigación. Centro de Estudios Sociológicos, El Colegio de México. 
es atribuible a la confusión que existe respecto a lo que debe entenderse por productividad. Esta por lógica debe referirse al trabajo realmente invertido en la producción (número de horas, días, meses) y no al tamaño de la fuerza de trabajo (número de personas involucradas). Así, para mantener constante el producto, si no se modifican la cantidad de bienes de capital disponible, las técnicas productivas, ni las condiciones institucionales, la cantidad de trabajo invertida (insumo trabajo) también será constante. En estas condiciones, la "productividad media de los trabajadores”, será una función del tamaño de la fuerza de trabajo, pero esto no significa que su "productividad marginal" sea igual a cero; sino sólo que un aumento en la fuerza de trabajo no implica un aumento del insumo trabajo. ${ }^{4}$

A través de esta definición se ha tratado de dar una expresión cuantitativa a la subutilización de la fuerza de trabajo: en la medida en que los trabajadores permanecen ociosos, o sean improductivos, constituyen una fuerza de trabajo excedente. Esto implica la introducción de criterios o normas de "empleo satisfactorio" que poco tienen que ver con la realidad imperante. El subempleo es la diferencia entre esa norma y el trabajo real. Con frecuencia se mide como la diferencia entre el número de trabajadores disponibles y los que se "requieren" para hacer el trabajo. $\mathrm{O}$ bien la norma se deriva de la productividad de la mano de obra en unidades con un producto por trabajador relativamente alto; esta productividad se aplica a aquellas unidades con menor producto por trabajador y se determina así la fuerza de trabajo ideal, y a la diferencia entre ésta y la fuerza de trabajo real, se considera subempleo.

Ante la dificultad de manejar y medir el concepto de productividad marginal para estimar el subempleo (y tal vez como consecuencia de las severas críticas de que ha sido objeto la tesis de productividad marginal igual a cero), en la XI Conferencia Internacional de Estadígrafos del Trabajo, se hizo un intento por aclarar el concepto de subempleo. En tal intento se identificaron las siguientes categorías:

a) subempleo visible, que abarca a las personas que involuntariamente trabajan a tiempo parcial o durante períodos inferiores al período normal de trabajo;

b) subempleo invisible, que existe cuando el tiempo en que trabaja una persona no es anormalmente reducido, pero cuyo empleo es inadecuado en otros aspectos tales como:

i) cuando su trabajo no permite la plena utilización de sus mejores calificaciones o de su principal capacidad;

ii) cuando las ganancias que obtiene del empleo son anormalmente reducidas;

iii) cuando está empleada en un establecimiento o unidad económica cuya productividad es anormalmente baja.

4 G. Myrdal, op. cit., Vol. III, pp. 2050-2052. 
El subempleo que se produce en las situaciones indicadas en b), i) y
ii) suelen denominarse subempleo encubierto, en tanto que la situación
correspondiente a b), iii) se designa como subempleo potencial.
Mediante estas precisiones suplementarias se subraya que la definición de
subempleo queda "abierta", en el sentido de que puede aplicarse a cual-
quier situación de deficiencia cualitativa o cuantitativa del empleo, que
diversas categorías de subempleo pueden superponerse parcialmente (ex-
cepto las categorías visible e invisible) y que en tanto que la categoría
visible tiene contornos bien precisos, la categoría invisible es un comodín
aplicable a otros tipos de deficiencia del empleo además de los expresa-
mente indicados.

Con estas aclaraciones encaminadas a facilitar la medición del subempleo, no se hace sino ampliar la cobertura del concepto; lo que nos aleja aún más de la posibilidad de entender el fenómeno ocupacional, ya que bajo el término subempleo se engloba un conjunto de situaciones que pueden tener muy distinto significado. El subempleo (en especial el invisible), según la interpretación que se haga de las categorías mencionadas puede significar (en el mejor de los casos), cualquier situación ocupacional que difiera de lo que es típico en los países capitalistas desarrollados y puede adquirir cualquier magnitud según la norma que se establezca para medirlo. Por ejemplo, pueden considerarse subempleados todos aquellos trabajadores (asalariados o por cuenta propia) que perciban por su trabajo, un ingreso inferior a determinada cantidad, aun cuando trabajen incluso más de la jornada "normal", e independientemente de sus características individuales como edad y estado de salud. Se corre entonces el riesgo de confundir subutilización, explotación e incapacidad para trabajar.

En el afán de interpretar estas "categorías del subempleo", se ha llegado a una confusión conceptual extrema, al grado de hacer equivalente el subempleo al concepto marxista de plusvalía absoluta, ${ }^{6}$ como se deduce de la cita que se incluye a continuación y que se refiere a una interpretación del Prealc (Programa Regional del Empleo para América Latina y el Caribe) a la modalidad de subempleo invisible indicada en $b$ ), ii).

"Conceptualmente los trabajadores permanentes producen un cierto valor agregado, recibiendo como compensación un determinado salario.

5 Organización Internacional del Trabajo, Medición del subempleo. Conceptos $y$ métodos, XI Conferencia Internacional de Estadígrafos del Trabajo, Ginebra, 1966, pp. 17-19. Citado por Clara Jusidman, "Conceptos y definiciones en relación con el empleo, desempleo y el subempleo”, Demografía y Economía, El Colegio de México, Vol. V, Núm. 3, 1971.

6 "La producción de plusvalía absoluta se consigue prolongando la jornada de trabajo más allá del punto en que el obrero se limita a producir un equivalente del valor de su fuerza de trabajo y haciendo que este plustrabajo se lo apropie el capital. La producción de plusvalía absoluta es la base general sobre la que descansa el sistema capitalista...", Carlos Marx, El capital, México, Fondo de Cultura Económica, 1974, p. 426. 
Cuando éste es notoriamente inferior al primero, se genera una situación de despojo de los frutos del trabajo, que se califica como subempleo, de acuerdo con la segunda condición enumerada ... " 7

La limitación fundamental de la teoría moderna del subempleo como marco analítico del problema ocupacional de los países de escaso desarrollo relativo, radica en establecer la premisa de que se trata sólo de un problema de subutilización de la fuerza de trabajo, reductible a un común denominador, subutilización que difiere de la que se da en los países capitalistas desarrollados únicamente en que no se manifiesta de manera preferente en desempleo abierto (personas que concurren al mercado de trabajo en busca de empleo, sin encontrarlo), sino que se esconde atrás de ocupaciones "inadecuadas".

Esta teoría soslaya el hecho de que la presencia de formas de producción no capitalistas, el diferente desarrollo de las fuerzas productivas entre sectores económicos y entre unidades productoras, las distintas formas de inserción de los diferentes grupos sociales en la economía en conjunto, los bajos niveles educativos de una parte de la población, y en fin todos aquellos aspectos que caracterizan el subdesarrollo, dan origen a una compleja gama de situaciones ocupacionales con implicaciones muy distintas.

A pesar de que en algunos de los estudios más recientes, se ha cuestionado la validez y relevancia del marco teórico y su utilidad para la definición de políticas, y aun cuando se reconoce que aspectos tales como la heterogeneidad tecnológica y los diferentes modos de producción, tienen significativas consecuencias sobre la utilización de la fuerza de trabajo; en estos análisis, subyace la idea de que el problema ocupacional se reduce a una subutilización de los recursos humanos. ${ }^{8}$

Para poder salir de este embrollo conceptual, es necesario partir de una observación de la realidad que permita determinar las distintas modalidades que adoptan no sólo la subutilización, sino la utilización misma de la fuerza de trabajo, y desarrollar entonces los conceptos apropiados a esa realidad, en lugar de tratar de adaptar ésta a conceptos preestablecidos e inadecuados.

\section{ESTUdios SOBRE DESEMPLEO Y SUBEMPLEO EN MÉXICO}

Bajo la influencia de la teoría moderna del subempleo, los principales esfuerzos que se han canalizado al análisis del problema ocupacional en México, se concretan en esencia a estimar el grado del "desempleo" o "subempleo" en términos de la productividad media, del ingreso percibido

7 Instituto de Planejamento Económico e Social, Sistemas de información para politicas de emprego, Brasilia, 1975, p. 255.

8 Véase al respecto, Instituto de Planejamento Económico e Social, op. cit. 
o del número de meses trabajados por persona ocupada, por sectores económicos o específicamente en el sector agrícola. Una vez hechas estas estimaciones, con frecuencia se ofrecen explicaciones de carácter general acerca de las causas que provocan el subempleo. Entre estas causas se señalan la estacionalidad de la actividad agrícola, la creciente mecanización, y en especial la explosión demográfica y la insuficiente absorción de mano de obra por parte del sector industrial, pero sin ninguna evidencia o hipótesis fundamentada de la relación causa-efecto.

Como ejemplos ilustrativos de los estudios que sobre el problema ocupacional se han realizado en el país, a continuación se reseñan y comentan en forma breve tres de los más recientes y de mayor difusión: uno realizado por el Centro de Investigaciones Agrarias a fines de los años sesenta; ${ }^{9}$ otro elaborado por Manuel Gollás en $1970^{10}$ y uno más realizado en 1973 por un grupo de técnicos auspiciado por el gobierno federal para analizar el problema ocupacional en México. ${ }^{11}$

\section{Estudio del Centro de Investigaciones Agrarias}

En el estudio realizado por el Centro de Investigaciones Agrarias, se destinan algunas partes al análisis del empleo y el desempleo entre productores de bienes agropecuarios.

En el capítulo III, se presentan los principales datos encontrados en encuestas regionales a nivel de predio, ${ }^{12}$ sobre el número de días efectivamente trabajados en las labores del predio y sobre la distribución del esfuerzo laboral de la familia en el predio y fuera de él en términos de días-hombre al año. Asimismo, se of recen cifras sobre el ingreso generado dentro y fuera del predio.

Los predios se clasifican en cinco estratos a partir del valor de su producción, según si éste era o no suficiente para mantener a una familia rural típica. Dentro de cada estrato se hicieron distinciones entre grupos de productores (predios pivados, parcelas ejidales, sociedades ejidales y arrendatarios) y según tipos de suelo (de riego o temporal).

Por lo que respecta al trabajo en el predio agrícola, se encontró que el total de días-hombre invertidos efectivamente aumenta con el volumen de la producción de estrato a estrato, como puede observarse en el cuadro 1 que se refiere al tiempo medio de trabajo efectivo (incluido tanto el de los productores y sus familiares como el de los asalariados), según los distintos estratos de producción.

9 Varios autores, Estructura agraria y desarrollo agrícola en México, op. cit., Capítulo III, pp. 261-268 y capítulo IV, pp. 322-332.

10 Manuel Gollás, "El desempleo y el subempleo agrícolas en México", en Edmundo Flores (Comp.), Desarrollo Agrícola. Lecturas 1, México, Fondo de Cultura Económica, 1974.

11 Grupo de Estudios del Problema del Empleo, El problema ocupacional en México. Magnitud y recomendaciones.

12 Las encuestas se realizaron en 1968. 
Sin embargo, aunque los estratos con mayor producción utilizan más. días-hombre al año, no lo hacen en proporción al producto adicional, ni en relación a la disponibilidad de tierra y capital. Se encontró que tanto la relación días-hombre por hectárea, como la relación días-hombre por unidad de capital por lo general aumentaban entre los estratos I y II, pero bajaban nuevamente a partir del estrato III o IV (véase el cuadro 1).

Cuadro 1

LÍMITES MEDIOS DE TRABAJO EFECTIVO EN EL PREDIO

\begin{tabular}{ccc}
\hline Estratos & $\begin{array}{c}\text { Dias-hombro } \\
\text { al año }\end{array}$ & Bombres-año \\
\hline I. Infrasubsistencia & $75-150$ & $0.25-0.50$ \\
II. Subfamiliares & $250-350$ & $1-1.5$ \\
III. Familiares & $500-650$ & $2-3$ \\
IV. Multifamiliares medianos & $600-1300$ & $3-5$ \\
V. Multifamiliares grandes & $3000-8000$ & $12-30$ \\
\hline
\end{tabular}

Fuente: Estructura agraria y desarrollo agrícola en México, op. cit., p. 262.

Se observó que había diferencias en el número de días-hombre utilizados entre tipos de productores pertenecientes a un mismo estrato, pero tales diferencias parecen haber estado asociadas a los cultivos en explotación (según fueran más o menos intensivos en el uso de mano de obra).

En todos los estratos, el índice días-hombre por hectárea resultó dos o tres veces mayor en los predios de riego que en los de temporal.

En cuanto a la distribución del trabajo entre el productor y sus familiares y los asalariados, se encontró que la importancia del trabajo asalariado está en relación directa con el estrato: en los predios de infrasubsistencia entre el 10 y el $15 \%$ de las jornadas eran desempeñadas por jornaleros y en los predios multifamiliares esta proporción era del 60 al $80 \%$. También se observó que la importancia del trabajo de asalariados era menor entre los ejidos que entre los predios privados.

Sin tomar en cuenta el trabajo asalariado, el empleo familiar medio en el predio era de menos de 100 días-hombre en el estrato I, de 200 a 250 días en el II y de 300 y más a partir del estrato III.

Estas cifras ponen de manifiesto que la mayor parte de los predios agrícolas no permiten utilizar la mano de obra familiar disponible, pese a lo cual la estacionalidad que caracteriza a la actividad agrícola obliga a los campesinos a contratar mano de obra asalariada en las épocas de actividad más intensa.

En cuanto al número de días-hombre trabajados por el productor y sus familiares dentro y fuera del predio, se encontró que la importancia relativa del trabajo realizado por la familia fuera del predio, cambiaba en razón inversa a los estratos. Los agricultores pertenecientes al estrato I invertían en su predio entre el 19 y el $40 \%$ de los días trabajados al 
año, los del estrato II poco más del $60 \%$ y a partir del estrato III, el predio absorbía más del $70 \%$ del trabajo anual del productor.

Por lo que se refiere al ingreso generado dentro y fuera del predio, las encuestas realizadas por el Centro de Investigaciones Agrarias reflejan que en el estrato I casi la totalidad del ingreso provenía de las actividades fuera del predio; en el estrato II este porciento fluctuaba entre el 50 y $75 \%$. Aún en los predios clasificados como familiares (estrato III), las familias derivaban entre el 25 y $50 \%$ de su ingreso de fuentes externas al propio predio y sólo a partir del estrato IV se reduce este componente al $10 \%$.

Con relación al tipo de ocupaciones que desempeñaban los productores fuera del predio, el estudio que se analiza señala que los productores de infrasubsistencia trabajaban fuera de su predio principalmente como jornaleros del campo y que la proporción de propietarios-jornaleros disminuía al pasar de un estrato a otro. Por el contrario, la proporción de agricultores que trabajan en actividades no agrícolas aumenta con el estrato. También se encontró que los ejidatarios trabajaban como jornaleros del campo con mayor frecuencia que los propietarios privados del mismo estrato. Esto puede reflejar que los propietarios privados tengan mayores oportunidades ocupacionales fuera del predio que los ejidatarios, como resultado de contar con mejor calificación o por el hecho de poder realizar inversiones en otras ramas de actividad.

En una sección del cuestionario utilizado en estas encuestas, se preguntó al productor cuántos días al año estuvo desocupado. El 54\% de los propietarios privados, el $73 \%$ de los ejidatarios y el $91 \%$ de los miembros de sociedades ejidales declararon haber estado desempleados durante algún tiempo del año. En los estratos I y II (de infrasubsistencia y subfamiliares), la desocupación era de entre 100 y 150 días; en los estratos III y IV, los productores reportaron haber permanecido desocupados de 50 a 100 días y en el estrato $\mathrm{V}$, de 10 a 20 días al año. La situación resultó muy similar entre productores privados y ejidatarios, a excepción del estrato IV donde los ejidatarios reportaron mayor número de días desocupados que los propietarios.

No se captó si estas cifras se refieren a desempleo voluntario o involuntario. Sin embargo, es probable que por lo menos una parte de esta desocupación sea voluntaria. Si se suman el número de días trabajados por el productor (dentro y fuera del predio), con el número de días desocupados, el resultado es en casi todos los casos superior a los 300 días anuales (véase cuadro 2). Tal resultado parece excesivo si se le compara con el número total de días al año que se consideran como hábiles en las áreas rurales en diferentes estudios. ${ }^{13}$ Aún en las áreas urbanas de

13 En otras partes del estudio a que se hace referencia se considera que el número de días disponibles para el trabajo en áreas rurales es de 250 a 280 . En estudios antropológicos realizados principalmente en comunidades indígenas se consideran de 235 a 250 días hábiles. 


\section{Cuadro 2}

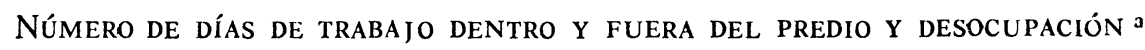
(Media por estratos y grupos de tenencia)

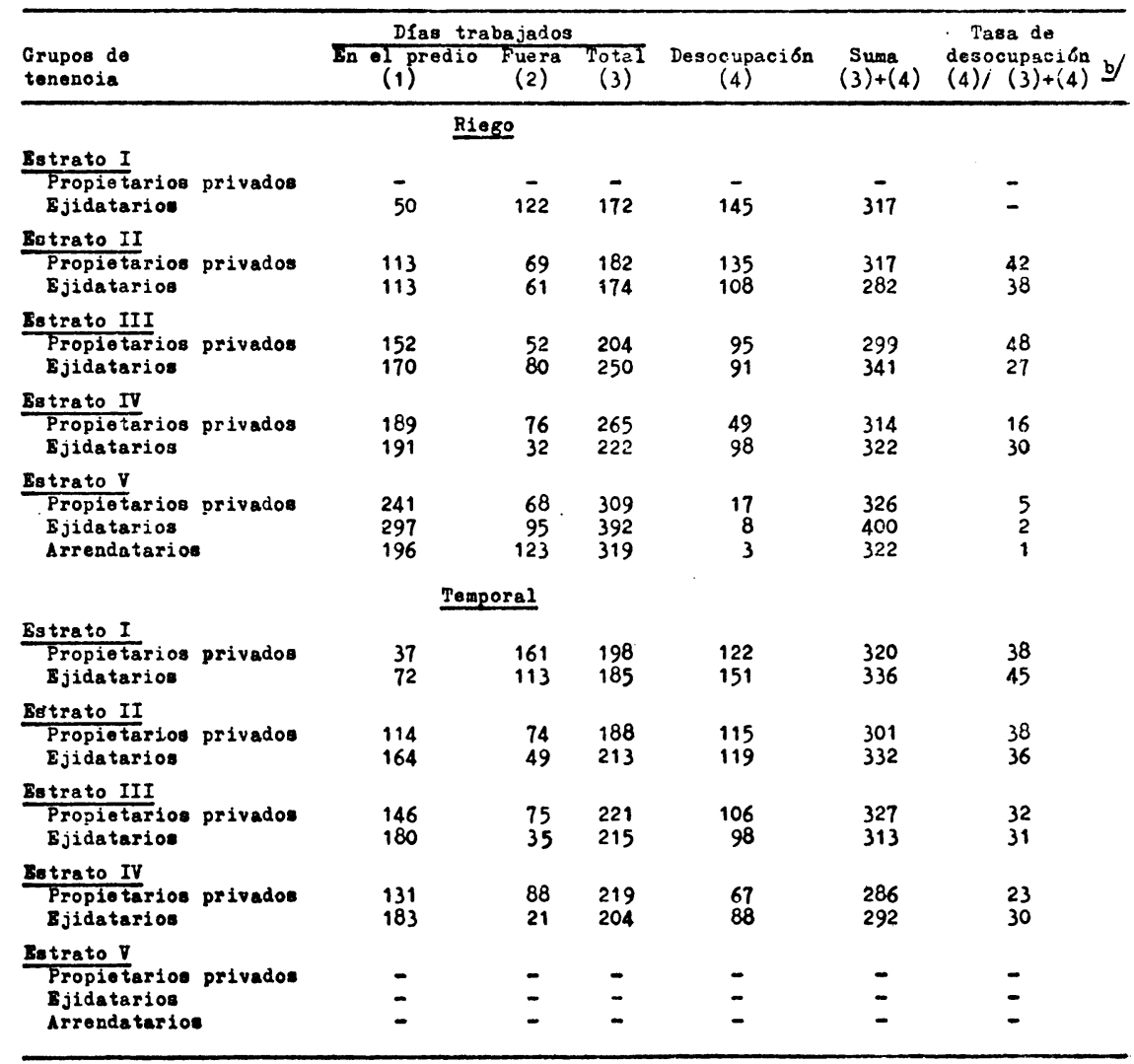

Fuente: Estructura agraria y desarrollo agrícola de México, op. cit., p. 1069.

a No se incluyen cifras sobre sociedades ejidales, porque no se especifica el tiempo trabajado dentro de la sociedad.

b Porcientos.

México, el número de días que por lo común laboran los asalariados es inferior a 300 días (entre 230 y 290 días).

Otro indicador de que el desempleo manifestado por los productores entrevistados puede ser voluntario, por lo menos en parte, es el hecho de que el número de días que trabajaron los productores del estrato $\mathrm{V}$ excede de 300 .

En atención al número de días efectivamente trabajados durante el año, sólo en los estratos I y II se refleja una considerable subutilización de la fuerza de trabajo de los productores (sea o no voluntaria). Respecto a la utilización de la fuerza de trabajo del resto de los miembros de la 
familia, la información que ofrece este estudio no permite derivar conclusiones.

En el capítulo IV del estudio del Centro de Investigaciones Agrarias a que se hace referencia, se intentó evaluar la magnitud del problema del desempleo rural a nivel nacional, con estimaciones gruesas basadas en los censos agropecuarios y coeficientes aproximados de mano de obra por hectárea y por productos animales.

Se calculó el número total de días-hombre requeridos en la agricultura durante el año de 1960, mediante coeficientes técnicos por cultivo y por superficie cultivada. También se estimó el número de días-hombre requeridos para la administración de los predios agrícolas, bajo el supuesto de que se necesitan cinco días-hombre al año por hectárea sembrada. Asimismo se calculó el número de días-hombre al año en ganadería y avicultura en el supuesto de que por cada peso de productos animales, se requiere una tercera parte de días-hombre.

Estas estimaciones se hicieron para predios privados menores de cinco hectáreas, mayores de cinco hectáreas y para parcelas ejidales. De acuerdo con lo anterior, resultó que los predios mayores de cinco hectáreas requieren en término medio de 1000 días-hombre al año, frente a 200 días-hombre en las parcelas ejidales y sólo 60 en los predios privados menores de cinco hectáreas.

Para cuantificar la forma en que se repartían estos días-hombre entre el productor (incluidos sus familiares) y los asalariados, se estimó el total correspondiente a jornaleros al dividir el total erogado por salarios que reportó el censo agropecuario de 1960 entre el salario mínimo diario en el campo (media nacional).

En los predios privados mayores de cinco hectáreas, la diferencia entre el total de días-hombre requeridos y los días-hombre cubiertos por jornaleros se distribuyó entre el jefe del predio y sus familiares, aparceros, empleados y otros (no se explica la metodología utilizada para hacer esta asignación).

En el caso de los predios privados menores de cinco hectáreas y las parcelas ejidales, la diferencia entre los requerimientos totales de trabajo y la parte asignada a los jornaleros, se atribuyó al productor y sus familiares. Este cálculo dio como resultado que las parcelas ejidales proporcionaban 180 días de ocupación (media anual) al agricultor y su familia y los predios privados menores de cinco hectáreas, sólo 36 días anuales.

En seguida se procedió a calcular el grado de desempleo de estos dos grupos de productores, al suponer que no desempeñaban ninguna actividad económica fuera del predio; supuesto que se contradice con los resultados obtenidos en el capítulo III del mismo estudio.

Se obtuvo entonces una tasa de desempleo ${ }^{14}$ de $25 \%$ para los ejida-

14 La tasa se obtiene al dividir la diferencia entre los días-hombres requeridos en actividades agropecuarias, y los días hombre cubiertos por jornaleros, entre el 
tarios y de $86 \%$ para los propietarios de predios menores de cinco hectáreas, con el supuesto adicional de que el trabajo del predio (descontando el trabajo de asalariados), está a cargo exclusivamente del jefe del mismo, es decir, se excluye la participación de su familia. ${ }^{\mathbf{1 5}}$

Como si se tratara de dos formas alternativas igualmente válidas de medir el desempleo, se hizo el mismo cálculo con la inclusión no sólo de los propietarios, sino también de sus familiares mayores de quince años, con lo cual las tasas de desocupación se elevan a $58 \%$ para los ejidos y a $92 \%$ en los predios privados pequeños.

\section{El desempleo y subempleo agrícolas (Manuel Gollás)}

El trabajo de M. Gollás, consistió en la elaboración de distintas estimaciones sobre la utilización de la mano de obra en el sector agrícola de acuerdo a dos criterios: la productividad de la fuerza de trabajo y el tiempo efectivamente trabajado en la agricultura. Los cálculos se hicieron con base en cifras de los censos de población y de los censos agrícolas para 1950 y 1960 y con cifras proyectadas para 1970.

En cuanto a la medición del subempleo en términos de productividad, el método utilizado consistió en identificar un grupo de predios agrícolas cuya productividad media (valor de la producción por trabajador) fuera reducida en relación con la de otros grupos. A las personas ocupadas en el grupo de predios con baja productividad se les consideró como subempleados. Se calculó entonces la fuerza de trabajo excedente como la diferencia entre el número de personas ocupadas en ese tipo de predios, menos el que se requeriría para lograr el mismo producto, si la productividad fuera la de otro grupo tomado como norma. La fuerza de trabajo excedente, calculada de esta forma se denominó por el autor como desempleo equivalente.

A la cifra de desempleo equivalente se le añadieron los desempleados visibles (o abiertos) en la agricultura y, en 1960, se sumaron también los niños de 8 a 11 años que trabajaban en el sector y a esta suma se le denominó desempleo total. ${ }^{16}$ Por último se calcularon las tasas de desempleo (equivalente y total) en relación con la población económicamente activa que reporta el censo de población, mientras el desemplo equivalente se calculó con base en el censo agrícola.

producto que resulta de multiplicar el número de productores por 250 (bajo el supuesto de que el número de días hábiles en las áreas rurales es de 250).

15 Esta forma poco realista de medir el grado de desocupación de la fuerza de trabajo. y que obviamente induce a sobreestimar tal problema, se ha generalizado en los últimos tiempos. Véase por ejemplo, prealc, El problema del empleo en América Latina. Situación perspectivas y políticas, ort, Santiago de Chile, abril de 1976, pp. 261-265.

16 El autor no aclara cómo asignó el desempleo abierto que reporta el censo de población, entre sectores, ni por qué considera a los trabajadores menores de 12 años como desocupados. 
El autor supone que en el grupo de predios donde la productividad por trabajador es baja, la productividad marginal es igual a cero, pues para que se lograra la productividad media fijada como norma, bastaría con eliminar el trabajo redundante, sin que se reconozca la necesidad de introducir mejoras tecnológicas o de organización. ${ }^{17}$ Con base en este método, se hicieron dos estimaciones distintas para cada una de las tres fechas consideradas. En un primer caso se consideró como desempleados a los jefes de aquellos predios cuyo valor de la producción anual era de mil pesos o menos, y la productividad media que se tomó como base para estimar el desempleo equivalente, fue la de los predios con una producción anual con valor de 5000 a 25000 pesos. Las tasas de desempleo equivalente (respecto a la PEA agrícola total del censo de población) resultaron de $26.0 \%$ para $1950,19.5 \%$ para 1960 y $14.5 \%$ para $1970 .^{18}$

En otra estimación, se consideró como subempleados a todas las personas ocupadas en los predios menores de 5 hectáreas y se usó como norma para determinar el desempleo equivalente, la productividad media de los predios mayores de 5 hectáreas y ejidos. En este caso las tasas de desempleo equivalente (respecto a la PEA agrícola total del censo de 1960) fueron de $8.7 \%$ en 1950 ; de $13.8 \%$ en 1960 y de $21.7 \%$ en $1970 .^{19}$

Como se puede observar, de acuerdo con las primeras estimaciones, el desempleo tiende a aumentar y de acuerdo con las últimas, a disminuir, lo cual se debe a que en las primeras sólo se incluyó a los propietarios (privados y ejidales) de predios de infrasubsistencia, quienes han disminuido en el tiempo en términos absolutos; mientras en las segundas estimaciones se incluyó también a los jornaleros (o asalariados), que representan una proporción cada vez mayor de la PEA agrícola.

Por otra parte, Gollás midió el desempleo agrícola en términos de tiempo trabajado, como la diferencia entre el potencial de días-hombre disponible y el total de días-hombre realmente utilizados.

El potencial de días-hombre disponible se estimó al multiplicar el número de propietarios, de familiares mayores de 15 años y de jornaleros, por 300 (días), y el número de días-hombre utilizados se estimó aplicando coeficientes de producción por cultivo, a la superficie cosechada.

Una vez calculado el excedente de fuerza de trabajo en días-hombre, se dividió esta cifra entre 300 para obtener el desempleo, en númerc de personas.

De acuerdo con este criterio, la tasa de desempleo (respecto de la PEA

17 Manuel Gollás, op. cit., pp. 185-197.

18 Ibidem., cuadro 8, p. 206.

19 Ibid., cuadro 12, p. 211. Se hizo este mismo cálculo sólo para propietarios puros (ejidatarios y propietarios privados que no trabajaban como asalariados) para quienes la tasa de desempleo equivalente resultó de $5.7 \%$ en 1950 y de $2.5 \%$ en 1960 (no se calculó para 1970). 
agrícola del Censo de Población), resultó de $55.5 \%$ en 1950 , de $50.4 \%$ en 1960 y de $46.0 \%$ en 1970 .

Lo elevado de estas tasas se debe al supuesto que se hizo en el momento de calcular el número de días-hombre disponible: los propietarios (privados y ejidales) y los jornaleros de todas las edades, así como los trabajadores familiares mayores de 15 años, podían trabajar en la agricultura durante 300 días al año (a jornada completa) y estarían dispuestos a hacerlo; supuesto que parece poco realista. Implica por una parte, que estas personas no desempeñan ninguna otra actividad además de la agrícola, cuando se sabe que muchas de ellas realizan una serie de actividades que (indebidamente a nuestro juicio) no se consideran como económicas, pero que son indispensables para la subsistencia de las familias rurales, como son el acarreo de agua o de leña (que es usada como combustible); además, es común que los miembros de las comunidades rurales desempe. ñan durante varios meses del año (en especial en los períodos de menor actividad agrícola), otras actividades económicas (dentro o fuera de sus localidades), que resultan indispensables para complementar el presupuesto de las familias a que pertenecen. Por otra parte, el supuesto implica que la actitud hacia la vida y hacia el trabajo de los habitantes de las comunidades rurales, es la misma que se tiene en las sociedades industriales modernas.

\section{El problema ocupacional en México. Magnitud y recomendaciones (Grupo de estudios del problema del empleo, GEPE)}

En la primera parte de este estudio se calculó el subempleo para 1970 en términos del ingreso percibido. El método utilizado para este cálculo consistió en sumar el número de personas consideradas por el Censo de Población como económicamente activas, cuyo ingreso era inferior al menor de los salarios mínimos de cada entidad federativa, con el de aquellas personas que declararon ayudar a la familia sin retribución personal.

Este criterio se siguió, según se aclara en el mismo estudio, con el objeto de que se incluyera a:

“1. Las personas que trabajando a tiempo completo, obtienen ingresos anormalmente bajos.

2. Las personas que obteniendo ingresos iguales o superiores al 'normal' no trabajaron a tiempo completo el año de 1969, y que habiendo prorrateado su ingreso anual entre los 12 meses del año, declararon un ingreso mensual medio inferior al salario mínimo.

3. Aquellas personas que estando mejor capacitadas, obtienen ingresos iguales o inferiores al salario mínimo, constituyendo parte de los que no utilizan plenamente su capacidad.

4. Las personas que declararon ayudar a la familia sin remuneración en las actividades predominantemente tradicionales, personas que en 
su mayoría se encuentran en ocupaciones con niveles de productividad anormalmente bajos o nulos." 20

De esta manera quedan reducidas a un denominador común (el subempleo), un conjunto de situaciones ocupacionales que, salvo las bajas retribuciones, poco tienen en común, en especial en lo que respecta a los instrumentos de política económica a través de los cuales podrían superarse. Se incluyen tanto asalariados que pueden percibir ingresos menores al salario mínimo, por el simple hecho de que la oferta de mano de obra sea abundante, o porque sólo logran empleo una parte del año; así como trabajadores por cuenta propia cuyos reducidos ingresos pueden deberse a que cuenten con recursos productivos limitados o porque reciben un precio bajo por su producto, independientemente de que ocupen o no toda la fuerza de trabajo familiar de que disponen.

El hecho de que el $43 \%$ de la PEA remunerada (asalariados y trabajadores por cuenta propia), perciban por su trabajo un ingreso inferior al necesario para cubrir las necesidades básicas de una familia, constituye un problema más complejo (sobre el que debería atraerse la atención de los políticos), que el de subutilización de la fuerza de trabajo, y significa que la mayor parte de las familias mexicanas (en especial las rurales), no pueden vivir del trabajo de uno solo de sus miembros. ${ }^{21}$ Esto hace que muchas personas se incorporen a la fuerza de trabajo a edades muy tempranas (con lo que abandonan la escuela si es que tuvieron acceso a ésta), a cambio de cualquier ingreso, con lo que presionan sobre el mercado de trabajo y abaratan aun más los salarios. El bajo ingreso de los jefes de familia, parece ser también la causa principal de la creciente participación de la mujer en la fuerza de trabajo en México, donde la presión femenina sobre el mercado de trabajo proviene cada vez más de los estratos sociales más pobres. ${ }^{22}$

Por otra parte, encontramos de nuevo la tesis de productividad marginal igual a cero, la cual se atribuye de manera explícita sólo a los trabajadores familiares sin retribución. Por esta razón se les considera como subempleados, cuando en realidad la presencia de este tipo de trabajadores sólo significa que existen unidades productoras que basan en alguna

20 Grupo de Estudios del Problema del Empleo, op. cit., pp. 25-26.

21 Aun cuando las cifras censales subestiman los ingresos provenientes de actividades agropecuarias, ya que sólo se refieren a ingresos monetarios, mientras la producción agrícola se destina en una proporción considerable al autoconsumo (no sólo para la alimentación de la familia, sino para el pago en especie a trabajadores asalariados que complementa el salario monetario), estas cifras dan una idea de la magnitud del problema de ingresos suficientes. De acuerdo con los resultados de las encuestas sobre ingreso-gasto realizadas en el país, las familias más pobres son aquellas que viven principalmente de la agricultura.

22 T. Rendón y M. Pedrero, "Alternativas para la mujer en el mercado de trabajo en México. Mercados regionales de trabajo", Naciones Unidas-Instituto Nacional de Estudios del Trabajo, México, 1976. 
medida su producción en el trabajo familiar (versus el trabajo asalariado), aun cuando esto de ninguna manera implica que la productividad de estas personas tenga que ser necesariamente reducida y menos aún, nula; ni tampoco implica que estén parcialmente ociosas y dispuestas a trabajar más.

De acuerdo con el método señalado, se estimó que en 1970 había en el país 5.8 millones de personas subocupadas, que representaban el $44.8 \%$ de la PEA. De este total, la mayor parte (el 60\%), correspondió al sector agropecuario y le sigue en importancia el sector servicios (con 14.4\%). Al interior del sector agropecuario, los subempleados representaban más de las dos terceras partes de la PEA dedicada a este tipo de actividades.

La proporción de personas que perciben por su trabajo ingresos inferiores al salario mínimo o trabajadores familiares no retribuidos, varía de manera considerable de una región a otra. En las regiones del Golfo de México y la Península de Yucatán, más del $60 \%$ de la PEA total se encontraba en esa situación, en tanto que en las regiones Centro, Noroeste y Norte dicha proporción es de alrededor de $33 \%$. En términos absolutos, el problema es mayor en las regiones Centro y Distrito Federal y su área metropolitana, que son las de mayor concentración demográfica.

Una vez calculado el número de personas subocupadas en el país se procedió a calcular el desempleo equivalente, de la manera siguiente.

"La forma de cuantificación del desempleo equivalente implícito en los 5.8 millones de subocupados, consistió en acumular los ingresos declarados, dividiendo su total entre el ingreso normal (el más bajo salario mínimo en cada entidad federativa). Se obtiene así la cantidad de 2.8 millones de personas que, con base a lo anotado en el párrafo anterior, estarían plenamente ocupadas; por diferencia con el nivel del subempleo, se obtiene una cifra de tres millones de desempleo equivalente, o sea el 23 porciento de la población económicamente activa." 23

Esta cifra de desempleo equivalente se usa como un indicador del número de empleos que tendrían que crearse, si se quiere eliminar el subempleo. En el cálculo de este desempleo equivalente está implícito que todos los trabajadores que ganan poco, están parcialmente ociosos y que son perfectamente divisibles -o susceptibles de adición- no sólo el trabajo sino los trabajadores mismos, así como las fuentes de trabajo. Por ejemplo, tres personas que ganan 500 pesos, equivalen a una que gana 1500 , aun cuando pertenezcan a distintas familias y trabajen en diferentes unidades productoras de bienes y servicios, sin importar el tiempo que trabaje cada una de las tres personas.

A partir de estimaciones sobre PEA para 1980, basadas en proyecciones de la población en edad de trabajar y en su tasa de participación en la actividad económica en 1970 el GEPE deduce que, si se establece como

23 Grupo de Estudio del Problema del Empleo, op. cit., p. 30. 
meta mínima la de mantener el subempleo y el desempleo (prevalecientes en 1970), existe la necesidad de crear 6.8 millones de nuevos empleos en el período $1970-1980$ y 8.4 millones más en el decenio siguiente. Pero si se establece la meta de lograr el empleo pleno, habría que emplear produc. tivamente a los subempleados, los que equivalen a más de tres millones de desocupados.

Se hicieron entonces proyecciones a 1976 , de la capacidad de absorción de mano de obra de la economía mexicana, con el supuesto de que no habría cambios importantes en la estrategia de desarrollo y que se mantendría la tendencia a usar técnicas intensivas en el uso de capital.

De los resultados de estas proyecciones se concluye que, si no se realizan cambios sustanciales en la estructura económica, el crecimiento de la producción absorberá sólo una parte del incremento de la fuerza de trabajo, y por lo tanto el subempleo tenderá a aumentar

Con el fin de poder determinar los orígenes del desempleo y subempleo, el GEPE destina una parte importante de su estudio a analizar la evolución de la economía mexicana por sectores económicos y por regiones. En este análisis apoyan en buena medida diversas recomendaciones de política económica tendientes a superar el problema ocupacional, que constituyen la parte central del documento. Tanto en el análisis como en las recomendaciones, se hace especial hincapié en el sector industrial por considerar que es en este sector en el que debe basarse principalmente fa solución. Como el problema ocupacional se identifica con subutilización de la fuerza de trabajo y con la baja productividad (propias de los tra. bajadores por cuenta propia); la mayor parte de las recomendaciones se orientan a la creación de empleos asalariados en la industria y al aumento de la capacidad productiva de los trabajadores, más que a garantizar una mejor retribución al trabajo.

Por lo que se refiere al sector agropecuario, el análisis se reduce a ver la evolución del producto generado y de la población ocupada, y se concluye que las principales causas del subempleo en el campo son el minifundismo en la "agricultura tradicional" (atribuido sobre todo al incremen. to demográfico) y la mecanización en la "agricultura moderna".

Para superar los problemas de subempleo y pobreza en el campo y frenar la migración rural-urbana, el GEPE sugiere que la política de desarrollo rural establezca los siguientes objetivos:

a) "Elevar el nivel medio de ingresos por predio en la agricultura tradicional, de tal manera que dicho ingreso sea suficiente para cubrir las necesidades mínimas de una familia rural; cuando esto no sea suficiente, complementar las actividades agrícolas con 'actividades de granja' o con industrias rurales;

b) Aumentar el volumen de la producción agrícola. El GEPE establece como mínimo, una meta de crecimiento del sector agrícola del 5\% anual y señala que esta meta no implica la autosuficiencia en la pro- 
ducción, sino el uso más redituable de los factores tierra, agua, capital y mano de obra."

Para el logro de estos objetivos se mencionan como medidas más importantes: asignar mayor prioridad dentro de la inversión agrícola a la agricultura tradicional de las regiones más atrasadas; incrementar la oferta de crédito al campo; orientar la política de investigación al desarrollo de técnicas e insumos adecuados a la agricultura de temporal y a la agricultura tropical y canalizar la "extensión" agrícola a este tipo de áreas; fomento de industrias rurales; educación y capacitación masivas de la población del campo; promover la fabricación de piezas y componentes destinada a empresas situadas en áreas urbanas (maquila); y promover la organización campesina.

De la revisión anterior se puede concluir que de los tres estudios mencionados, el único que proporciona información relevante respecto a las características del fenómeno ocupacional en las áreas rurales, es el que realizó el centro de Investigaciones Agrarias con base en investigación de campo, en tanto aquellos que se basan en enfoques simplistas y en el uso exclusivo de fuentes secundarias, proyectan una imagen distorsionada de la realidad rural.

\section{La REALidad ocupacional en el México ruRAL}

En los países capitalistas centrales, como consecuencia del desarrollo de las fuerzas productivas y de que el "modo" capitalista de producción ha alcanzado la exclusividad, existe una separación perfecta entre unidades productoras de bienes y servicios (empresas) y unidades consumidoras (familias). Las familias adquieren en el mercado prácticamente todos los bienes y servicios necesarıos para la satisfacción de sus necesidades. En estas circunstancias, la utilización de mano de obra se deriva de la demanda agregada de bienes y servicios.

En los países capitalistas periféricos, una proporción considerable de las familias (en especial las que habitan en determinadas regiones rurales) producen en gran medida sus propios satisfactores y adquieren en el mercado sólo algunos de ellos, para lo cual venden parte de los bienes que producen (sobre todo agrícolas) y parte de su fuerza de trabajo. Cabe insistir en que los bienes que estas familias intercambian son producidos según principios no capitalistas de producción, el objetivo es la satisfacción de las necesidades familiares. Además, como consecuencia del escaso desarrollo de las fuerzas productivas, en las áreas rurales de estos países no existe una marcada división del trabajo. Pero pese a que en los países de menor desarrollo relativo (en particular en las áreas rurales), la actividad económica difiere sustancialmente de lo que es típico en los países industrializados; en los estudios tradicionales sobre fuerza de trabajo, como ya 
se ha señalado, suele ignorarse esta realidad. Al partir de esquemas propios de sociedades industriales desarrolladas, se consideran como actividades económicas sólo aquellas que se llevan a cabo en relación con el mercado (sea de bienes o de fuerza de trabajo),$^{24}$ siempre y cuando se invierta en ellas un mínimo de tiempo establecido como norma y sean desempeñadas por personas que han alcanzado una edad mínima. Se tiene además la idea de que existe una perfecta división del trabajo: las personas realizan siempre una misma actividad, es decir se dedican en exclusiva a la agricultura, a los quehaceres domésticos, al comercio, a las artesanías, etc.

En el caso concreto de México, la estructura productiva de las áreas rurales es en apariencia poco compleja. Las principales actividades económicas son de tipo agropecuario como se refleja en el cuadro 3 , en el que se clasifica a la PEA de acuerdo a su principal rama de actividad. En las localidades de menos de 2500 habitantes, el 77\% de la PEA se dedica de manera principal a actividades agropecuarias y esta proporción disminuye al aumentar el tamaño de la localidad; en las localidades mayores de 10000 habitantes sólo el $80 \%$ se dedica a ese tipo de actividades.

\section{Cuadro 3}

MÉxico: Distribución de la población ECONÓMICAMENTE ACTIVA POR RAMA DE ACTIVIDAD Y TASA BRUTA DE PARTICIPACIÓN SEGÚN TAMAÑO DE LOCALIDAD, 1970

\begin{tabular}{|c|c|c|c|c|c|}
\hline & \multicolumn{5}{|c|}{ Localidades (segin número de habitantes) } \\
\hline & $\begin{array}{r}\text { Con } \\
2500\end{array}$ & $\begin{array}{l}\text { menos de } \\
\text { habitantes }\end{array}$ & $\begin{array}{l}\text { D. } 2500 \\
\text { a } 4999\end{array}$ & $\begin{array}{l}\text { De } 5000 \\
\text { a } 9999\end{array}$ & $\begin{array}{c}\text { Con } 10000 \\
\text { y más }\end{array}$ \\
\hline Total & & 100.0 & 100.0 & 100.0 & 100.0 \\
\hline $\begin{array}{l}\text { Aotividades agropecus- } \\
\text { rias }\end{array}$ & & 76.9 & 45.5 & 27.3 & 7.9 \\
\hline Industrial extraotivas & & 1.0 & 1.2 & 1.7 & 1.8 \\
\hline $\begin{array}{l}\text { Industria de transfor- } \\
\text { macion }\end{array}$ & & 6.1 & 16.4 & 22.4 & 25.1 \\
\hline Construcoibn & & 1.9 & 4.6 & 5.9 & 6.3 \\
\hline Comeroio & & 2.8 & 8.0 & 10.7 & 14.8 \\
\hline Sorvicios & & $11 \cdot 3$ & $24 \cdot 3$ & 32.0 & 44.1 \\
\hline Tasa bruta do actividad & & 25.7 & 26.1 & 26.5 & 28.6 \\
\hline
\end{tabular}

Fuente: Dirección General de Estadística, Secretaría de Industria y Comercio, Censo General de Población, 1970. Resumen General.

Sin embargo, el hecho de que la actividad principal en las áreas rurales sea la agricultura, no implica que la PEA clasificada como agropecuaria sólo desempeñe este tipo de actividades durante todo el año. Sea para la satisfacción directa de algunas de sus necesidades, para obtener

24 La única excepción es la producción de bienes agrícolas, que se supone son los únicos que pueden producirse para el autoconsumo. 
ingresos que complementen el ingreso agropecuario o para diversificar su inversión (en el caso de los agricultores acomodados), los trabajadores agrícolas realizan diversas actividades no agropecuarias.

En la mayor parte de las comunidades rurales del país, la producción de alimentos para el consumo familiar por lo común incluye desde el cultivo de bienes agrícolas y la crianza de animales, hasta la claboración final, pasando por la molienda de maíz, elaboración de tortillas, ${ }^{25}$ etc. Esto significa que en las áreas rurales el trabajo doméstico implica, en la mayor parte de los casos, la producción de un mayor número de bienes y servicios que en las áreas urbanas. Esta realidad debe tomarse en cuenta en los estudios sobre utilización de fuerza de trabajo, ya sea que se consideren estas actividades como productivas o por lo menos se tenga en cuenta que las personas que tienen a su cargo el trabajo doméstico no están inactivas (como por lo común se supone).

En las localidades rurales pequeñas y con población dispersa, no se dispone por lo general de agua entubada, ${ }^{26}$ lo que obliga a las familias a destinar parte de su tiempo y esfuerzo a conseguir este líquido, para lo cual a veces es necesario caminar varios kilómetros. Algo similar ocurre con el combustible necesario para la preparación de alimentos; aun en comunidades cercanas a centros urbanos, es frecuente que las familias tengan que cortar leña ${ }^{27}$ para este uso, pues ni los combustibles propios de las áreas urbanas (gas, petróleo y carbón) existen en el mercado local, ni la población tiene el poder adquisitivo para comprarlos. También es frecuente que las familias más pobres de las áreas rurales, destinen parte de su tiempo a la recolección de hierbas para complementar su alimentación. Asimismo, en muchas comunidades indígenas la confección de ropa aún se realiza a nivel familiar, mientras en la mayor parte de las comunidades rurales este tipo de bienes se adquieren en el mercado y provienen de los centros urbanos.

25 De acuerdo con investigaciones realizadas recientemente en México sobre el trabajo de la mujer en el México rural, puede decirse que en la molienda de maíz y la elaboración de tortillas para el consumo diario de una familia de tamaño medio, se invierten alrededor de tres horas de trabajo femenino. Kate Young, "La participación de la mujer en la economía campesina”, Instituto Nacional de Estudios del Trabajo (en prensa); y Mercedes Pedrero, "Presupuesto de tiempo de la mujer en México", Centro Nacional de Información y Estadísticas del Trabajo (en elaboración).

26 De acuerdo con el Censo de Población de 1970, en las localidades de menos de 2500 habitantes, el $66 \%$ de las viviendas carecen de agua entubada; en las localidades de 2500 a 4999 habitantes, $42 \%$; en las localidades de 5000 a 9999 habitantes, 29\%; en las localidades de 10000 a $19999,20 \%$, mientras en las localidades de 20000 o más habitantes el $13 \%$ de las viviendas carecían del mencionado servicio.

27 Según el estudio de Kate Young a que se hizo referencia, en una comunidad rural de la Mixteca Alta en el Estado de Oaxaca, las mujeres pasaban de una a dos horas diarias en el corte de leña y algunas de ellas lo hacían no sólo para el consumo familiar, sino para venderla a familias acomodadas. 
Otro aspecto importante de subrayar es que la mayor parte de las unidades agrícolas (economía campesina), basan su producción en el trabajo familiar. De allí que el trabajo de los menores y de las mujeres sea de importancia primordial para el funcionamiento de la unidad, y aun cuando en realidad parece existir una subutilización de la fuerza de trabajo tal subutilización tiende a exagerarse. Y se ignora el hecho de que, por lo menos durante algunos meses del año (aquellos de actividad agrícola más intensa), algunos miembros de la familia que aún no han alcanzado la edad de trabajar y mujeres sobrecargadas de actividades domésticas, se vean obligados a realizar árduas jornadas de trabajo en el predio, e incluso se vean con frecuencia en la necesidad de trabajar fuera de la unidad familiar.

De acuerdo con encuestas realizadas en varias comunidades rurales del Estado de México y Oaxaca en 1975, se encontró que por lo general, los niños participan de alguna manera en la actividad económica desde los siete años. Los hombres por lo general ayudan a su padre en las actividades del predio, y las mujeres se dedican al cuidado de los animales, aunque también ayudan en el predio cuando la familia está integrada en su mayoría por mujeres. Niños y niñas ayudan en el acarreo de leña y agua. Puede decirse que la mayor o menor participación de los niños está en función del tamaño y estructura por edades de la familia, así como del nivel de ingresos de la misma; y la división del trabajo entre hombres y mujeres depende de la composición por sexos del grupo familiar. ${ }^{28}$

Como los ingresos que obtienen las familias en la actividad agrícola (ya sea mediante la venta de su producto o de su fuerza de trabajo), en la mayor parte de los casos son insuficientes para cubrir sus necesidades, algunos miembros de las familias desempeñan de manera permanente o eventual actividades no agrícolas. La producción de artesanías para la venta es una actividad común en algunas comunidades rurales (en especial las indígenas). Se trata por lo general de una actividad complementaria a la agricultura y se lleva a cabo sobre todo durante los períodos agrícolas muertos, época en que son también frecuentes las migraciones temporales a regiones donde predomina la agricultura capitalista, o a las zonas urbanas.

\section{NECESIDAD DE UNA NUEVA ORIENTACIÓN}

El hecho de que los habitantes de las comunidades rurales de México produzcan una parte importante de sus satisfactores y el que deriven su ingreso monetario anual del desempeño de diversas actividades, son aspectos que deben considerarse si se desea hacer un análisis realista de la utilización de la fuerza de trabajo.

El análisis sectorial de la fuerza de trabajo resulta parcial y tiene sen-

28 Mercedes Pedrero, loc. cit. 
tido sólo en cuanto a evaluar la capacidad de los distintos sectores económicos para proporcionar ocupación e ingreso a población, pero no si se desea apreciar el grado de utilización de la fuerza de trabajo.

Para poder medir de manera correcta el mencionado nivel de utilización, es necesario conocer la gama de actividades tanto económicas como no económicas que realiza la población, ya que estas últimas determinan en gran medida el tiempo de que se dispone para trabajar.

Por otra parte, es importante destacar que no basta con analizar las características personales de los trabajadores (sexo, edad, nivel de calificación, etc.) y aislarlas del contexto familiar y social a que éstos pertenecen. Si se considera que la unidad de consumo es la familia (y no el individuo), es de esperarse que la decisión individual de participar en la fuerza de trabajo y la forma que adopte tal participación, guarde estrecha relación con su posición como miembro de la familia y con las características de la unidad familiar a la que pertenezca (nivel de ingreso, tamaño y estructura y de que se posean o no medios de producción). Así, muchos individuos -en especial las mujeres y los jóvenes- participan en la fuerza de trabajo como consecuencia del bajo nivel de ingreso percibido por el jefe de la familia, o por el hecho de que la familia posea medios de producción en cantidad tal que sólo sea factible explotarlos con mano de obra familiar. Asimismo, cuando el jefe de la familia se vea en la necesidad de vender su fuerza de trabajo para complementar el ingreso, otros miembros se ven obligados a sustituirlo total o parcialmente en el predio, lo que puede implicar una mayor cantidad de personas ocupadas en la agricultura, pero no necesariamente un incremento en el número de horas que la familia destina a esta actividad.

Por otra parte, no debe soslayarse el hecho de que en el caso de la economía campesina (y de otras formas de producción existentes en México), unidad productora y unidad familiar son la misma cosa, con lo que oferta y demanda de mano de obra se confunden.

En los últimos años la preocupación de muchos estudiosos del sector rural por entender el comportamiento de la economía campesina en México, se ha traducido en la realización de interesantes estudios al respecto, tanto desde el punto de vista teórico como empírico, en los que se toma a la familia en sus dos aspectos: como unidad productiva y como unidad de consumo. Estos estudios constituyen sin duda una importante contribución a la comprensión del complejo fenómeno de la ocupación en las áreas rurales, por lo que la difusión y mayor cobertura de los mismos se antoja indispensable.

Queda sin embargo un importante vacío; poco se sabe acerca del comportamiento como trabajadoras, de las familias totalmente desposeídas de medios de producción. Múltiples estudios entre los que pueden citarse los relacionados con la distribución personal del ingreso, sitúan a las familias de jornaleros agrícolas como el grupo más pobre de la sociedad mexicana; pero poco se sabe de los mecanismos que estas familias utilizan para lograr 
su subsistencia. Se desconoce, por ejemplo, si la proporción de miembros de la familia que trabajan es mayor o la edad a que se incorporan a la actividad económica es inferior, en comparación con otros grupos sociales.

De esta manera, a pesar de la aparente abundancia de material estadístico sobre PEA no existen bases suficientes para llevar a cabo un análisis satisfactorio acerca de la disponibilidad de mano de obra en el sector rural.

Para poder determinar tal disponibilidad y sus principales determinantes, se requiere de un análisis que utilice como unidad básica de observación a la familia y considere por lo menos:

a) El tamaño y estructura de la misma;

b) Las distintas actividades (económicas y no económicas) que realizan cada uno de sus miembros (sin establecer a priori límites de edad $\mathrm{c}$ de tiempo trabajado);

c) Los recursos productivos de que dispone la familia (incluída la calificación de sus miembros).

Esto permitiría por una parte conocer el verdadero monto de fuerza de trabajo utilizada y determinar hasta qué punto el aumento en la oferta de mano de obra es condicionado por la desigual distribución de la riqueza y, por otra parte, el conocimiento de las características de los trabajadores y de la unidad familiar a la que pertenecen permitirá una caracterización del fenómeno del empleo más acorde a la realidad rural del país.

Dado que el sector rural mexicano dista mucho de constituir un todo homogéneo, el tipo de estudios que se sugieren deberían hacerse a nivel regional, tratando de delimitar áreas relativamente homogéneas, ya que los análisis agregados, si bien permiten derivar tendencias nacionales son de poca utilidad para la determinación de medidas concretas de política económica y social. 